\title{
Records of Oceanographic Work in Japan.
}

UNDER this title the National Research Council of Japan has commenced the publication of a journal dealing with physical and chemical oceanography, fundamental marine biology, and fisheries tech nology. In the first number-March 1928-an account is given of the work done by the Imperial Marine Observatory and the Imperial Fisheries Institute, with well-equipped research vessels of 125 and 200 tons respectively, and of the new Marine Biological Station at Asamushi.

This station was completed in July 1924, with the aid of a government grant, as a marine station of Tôhoku University. It is now becoming a centre for the promotion of biological science in Japan.

Research workers and post-graduate students from other institutions are welcomed and provided with laboratory facilities to prosecute their own researches. In addition, living accommodation is obtainable either in a boarding house or in one of several residences attached to the station, the visiting investigator having only to defray the cost of meals. The list of papers which have already been published shows that the opportunities afforded have attracted workers on varied biological problems.

The buildings consist of an aquarium room with a number of tanks, a range of laboratories, including rooms equipped for physiological and biochemical research, while an additional large biochemical laboratory is now under construction. A unique feature of the station is a building half submerged in the sea at the shore line, the floor being about 6 feet below sea-level. Three aquaria along one wall are supplied with natural sea water, which is continuously being changed with the ebb and flow of the tide. Since the temperature and other conditions are quite similar to that of the open sea, animals can live under practically normal conditions.

The Japanese government is far-sighted in fostering biological research by providing these facilities in one of the most delightful summer resorts, so that the staff of their universities and other institutions may continue their researches during the summer vacations under pleasant conditions and without expense.

Investigations concerning the principles controlling life, such as are prosecuted every summer by visiting workers at marine biological stations, as Woods Hole in the United States, Plymouth in Great Britain, and elsewhere, are yielding results of widening interest. Thus the attention of physiologists is turning to the possibility of attacking many fundamental problems by experiments upon the tissues of simple marine animals-a method of attack which is leading towards the interpretation of the results of investigations which have hitherto been chiefly limited to land vertebrates. The great advances in knowledge which have increased the amenities of life during the past century, have usually arisen from such investigations of purely academic interest. To attract those relatively few individuals, usually engaged in teaching at the universities, who are capable and willing to carry out such original research during their vacations, is a worthy aim for any government, for thereby the community as a whole is likely to benefit - as it has benefitted already from the fruits of 'purely academic' research. Furthermore, it is economy, in the true sense of 8 much-used term, to utilise fully the resources of a country's scientific learning.

A list of papers and reports bearing on oceanography and published during 1927 shows that this subject is now receiving considerable attention in Japan, which is actively participating in the International Committee for the Oceanography of the Pacific, founded to carry out similar liaison work to the International Council in the North-Western Atlantic. Other countries taking part are the United States and Australia, where the building of a marine biological station is under consideration.

\section{Surface Actions. ${ }^{1}$}

G I. FINCH AND J. C. StImson.-The electrical condition of hot surfaces during the adsorption of gases. Part 2. When a nickel sheet is heated in vacuo or in contact with a gas it becomes electrically charged. The magnitude of the charge depends upon the temperature of the metal and its previous history of heating. At $850^{\circ} \mathrm{C}$. the charge due to $\mathrm{O}_{2}, 2 \mathrm{CO}+\mathrm{O}_{2}, 2 \mathrm{H}_{2}+\mathrm{O}_{2}, \mathrm{CO}_{2}, \mathrm{H}_{2} \mathrm{O}, \mathrm{H}_{2}$, $A$ and $\mathrm{N}_{2}$ could be removed within 45 minutes by evacuation to less than $10^{-5} \mathrm{~mm}$. On the other hand, the carbonic oxide charge could only be removed by ' burning off' with oxygen. The charge on nickel oxide in vacuo is the same as that on reduced nickel. Oxygen or hydrogen is far more active in charging the surface than either argon or nitrogen.

It is concluded, inter alia, that $(a)$ the charge on a hot metal surface in contact with a gas is due to an activation of adsorbed gas molecules; $(b)$ there are at least five different kinds of adsorption of a gas on a hot surface, ranging from a purely physical, electrically neutral adsorption or condensation to a definite stable chemical compound formation which is likewise electrically neutral.

P. C. Allen and C. N. Hinshelwood.-The catalytic decomposition of gaseous acetaldehyde at the surface of various metals. Experiments have previously been made to compare the kinetics of

${ }^{1}$ Abstracts of papers read before the Royal Society on Nov. 1.

No. 3082, VoL. 122] simple homogeneous reactions, such as the decomposition of nitrous oxide, with the corresponding catalysed reactions. In continuation, the catalytic decomposition of a more complex substance, acetaldehyde, the homogeneous decomposition of which is bimolecular, has been investigated. Electrically heated wires of gold, platinum, platinum-rhodium alloy and tungsten were used as catalysts.

The reaction at the surface of each of these metals involves two molecules of acetaldehyde, but for initial pressures of more than $150 \mathrm{~mm}$. tends to appear unimolecular owing to the saturation of the surface with adsorbed molecules. The mechanism suggested for the reaction is that molecules from the gas phase react with molecules adsorbed on the surface, when these latter molecules acquire the necessary energy of activation from the metal atoms.

A remarkable and unusual similarity is found between the different metals in respect of $(a)$ relation between reaction rate and pressure, $(b)$ heat of activation, and $(c)$ absolute rate of reaction. This would have suggested that the reaction really occurred in a zone of heated gas, were it not for the evidence that surface saturation controls the rate of reaction. The aldehyde adsorption is evidently of a loose, nonspecific kind. The hot wire does not appreciably modify the stability of the adsorbed aldehyde molecules (the heat of activation being nearly the same as for the homogeneous reaction), but merely acts as 
a source of energy. Examination of the molecular statistics of the reaction indicates that collisions between molecules from the gas and adsorbed molecules are inelastic, with a duration of $10^{-6}$ to $10^{-8}$ sec.

R. CHAPLIN.--The sorption of carbon tetrachloride at low pressures by activated charcoals. A detailed description is given of the apparatus and experimental technique by means of which the low-pressure sorption isothermals of pure carbon tetrachloride vapour on charcoal, in the absence of foreign gases, were determined. The pressures were measured by means of a Pirani hot-wire gauge; the quantities sorbed were determined by direct weighing. Various difficulties were encountered, due to the presence of traces of foreign gases and vapours in the charcoals and in the apparatus. Six charcoals of varying origin were employed. The pressure limits worked between were $2 \cdot 3 \times 10^{-1}$ and $1 \times 10^{-4} \mathrm{~mm}$. of mercury. Most work was done at $25^{\circ} \mathrm{C}$., but several series of isosteres were also obtained, which permitted of the indirect determination of isothermals at higher temperatures.

\section{Stream-flow. ${ }^{1}$}

$\mathrm{H}$ LEVY AND A. G. Forspyke.-The steady motion and stability of a helical vortex The characteristics of a right helical vortex are investigated as regards steady motion and stability. The steady forward motion along, and uniform rotation about, the axis is calculated for various angles of pitch ; a critical pitch exists, at which this rotation vanishes. An examination of the possible fundamental modes of vibration of the filament suggests further that this critical pitch marks the division between stable and unstable helices. The results are of importance in connexion with the extension of the Kármán vortex street to three-dimensional motion.

R. J. CorNish.-Flow in a pipe of rectangular cross-section. The paper contains the results of an investigation into the flow of water in a pipe of rectangular cross-section $1.192 \mathrm{~cm}$. by $0.402 \mathrm{~cm}$.

In the region of laminar motion the flow corresponded closely with that expected by calculation. The effect of the distance between the entrance to the pipe and the point at which pressures are measured is shown, and later in the paper is a note on the conclusions of Messrs. Davies and White (Proc. Roy. Soc., May 1928) from their observations of this effect. The critical value of $m S / v$ (where $m=$ hydraulic mean depth, $S$ = average velocity, $v=$ kinematic viscosity) is about the same for the rectangular section as for a circular section; the effect of the proportions of the channel on the critical value is deduced. In the region of turbulent flow the curve obtained by plotting $R / \rho S^{2}$ (where $R=$ resistance per unit area, $\rho=$ density) against $m S / v$ is approximately the same as that obtained by other workers on pipes of various sections.

Appendix 1 gives the actual numerical results of the experiments, and appendix 2 contains an outline of the mathematical solution of laminar flow in a pipe of rectangular section.

A. T. Doodson.-The analysis and prediction of tidal currents from observations of times of slack water. The problem of obtaining harmonic constants for the principal tidal constituents representing the current flow, from a knowledge of the times of slack water only, has been solved. The solution is not one of great exactness, but resulting predictions have been considered sufficiently accurate to be included in standard tide tables. The times of maximum current can be predicted, but the velocities of maximum currents can only be stated on an arbitrary scale unless a few values of maximum currents have been observed.

${ }^{1}$ Abstracts of papers read before the Royal Society on Nov. 1.

No. 3082 , Vou. 122]
The method can be applied to obtain fairly good approximations to the tidal elevation at a place, for the times of high and low water, or for the times of half-tide. Two variations of the method are given, one being suitable for the discussion of observations of all slack water times during a month and the other being suitable for the analysis of observations taken during daylight for a whole year.

\section{University and Educational Intelligence.}

Cambridge.--Prof. Dean, Trinity Hall, Mr. J. F. Cameron, Gonville and Caius College, and Mr. $\mathbf{H}$. Thirkill, Clare College, are among the newly elected members of the Council of the Senate. Mr. T. R. Parrington, Sidney Sussex College, has been appointed Strickland Curator in the Museum of Zoology.

The Gedge Prize for research in physiology has been awarded to Dr. W. A. H. Rushton, Pembroke College. Mr. F. H. Woodward has been elected to a fellowship at Selwyn College. A grant of $£ 50$ has been made from the Balfour Fund to Dr. S. M. Manton, Girton College, for research on the biology and development of the Syncarida.

Mr. F. J. M. Stratton, fellow and senior tutor of Gonville and Caius College, has been elected to succeed Prof. H. F. Newall in December next as professor of astrophysics.

Texw following free public lectures in connexion with the Armourers and Brasiers' Company are announced : "Certain Aspects of the Solidification of Metals and Alloys," by Dr. S. W. Smith, at the Sir John Cass Technical Institute, on Nov. 28, Dec. 5 and 12, at 8.15 ; and "The Manufacture of Tinplate," by Dr. C. A. Edwards, at the Borough Polytechnic Institute, on Nov. 29, Dec. 7 and 14, at 5.30. No tickets will be required.

Education in India in 1925-26 is dealt with very briefly in a report issued by the Educational Commissioner with the Government of India last May. The report shows that the percentage of males under instruction in recognised institutions, although still small $(6 \cdot 5)$ increased rapidly during the ten years following 1916, when it was only $4 \cdot 7$. During the same period the percentage of females under instruction increased even more rapidly, namely, from 0.9 to 1.3. The cost of education is rising fast, the expenditure in 1925-26 having been 10 per cent higher than in the preceding year. Under the heading of higher education, universities show a slight decrease in the number of students, arts colleges an increase of 8 per cent, and professional colleges an increase of 3 per cent. There was a falling off in the numbers of medical, veterinary, forest, and commercial college students and of men students in teacher-training institutions. The scheme for founding a university in Rajputana was abandoned owing to the lack of support from the Native States. The report refers to the constitution of a new affiliating university at Agra, and another (the Andhra or Telugu) at Bezwada, and a project for establishing a Tamil university. Statistics of university students show a total of 96,158 in 16 universities. Calcutta, with 31,496 students, must be almost, if not quite, the largest, in point of numbers, in the world. Seventy-five per cent of the total number of students enrolled belonged to the four universities of Calcutta, Madras, the Punjab, and Bombay. An article on Indian students in Great Britain shows a notable decrease from 583 in 1925 to 390 in 1926 in the number of Indians studying in the Inns of Court. Nearly 200 were preparing for degrees or diplomas in engineering, and more than 100 were studying medicine; 147 (including 21 women) were government scholars. 